\title{
AMBIENT TEMPERATURE IMPACT ON MICRO GAS TURBINES: EXPERIMENTAL CHARACTERIZATION
}

\author{
IAcopo Rossi*, Alberto Traverso
}

\author{
Thermochemical Power Group - University of Genoa, 16145 Genoa, Italy \\ * corresponding author: iacopo.rossi@edu.unige.it
}

\begin{abstract}
In the panorama of gas turbines for energy production, a great relevance is given to performance impact of the ambient conditions. Under the influence of ambient temperature, humidity and other factors, the engine performance is subject to consistent variations. This is true for large power plants as well as small engines. In Combined Cycle configuration, variation in performance are mitigated by the HRSG and the bottoming steam cycle. In a small scale system, such as a micro gas turbine, the influence on the electric and thermal power productions is strong as well, and is not mitigated by a bottoming cycle. This work focuses on the Turbec T100 micro gas turbine and its performance through a series of operations with different ambient temperatures. The goal is to characterize the engine performance deriving simple correlations for the influence of ambient temperature on performance, at different electrical loads. The newly obtained experimental data are compared with previous performance curves on a modified machine, to capture the differences due to hardware degradation in time. An active management of the compressor inlet temperature may be developed in the future, basing on the analysis reported here.
\end{abstract}

KEYwORDS: Turbine flexibility, ambient temperature, micro turbine, cogeneration, experimental analysis.

\section{INTRODUCTION}

The penetration of renewables is pushing the need for flexibility even further in the energy generation environment [1, 2]. Together with deregulation of energy markets, non-dispatchable sources increased the need for traditional power plant of providing ancillary services to the electrical grid. The consequence is that power plants undergo several rapid transients during operations as well as daily startups and shutdowns. In this environment, gas turbine power plants are very much considered for their capability in being flexible and capable of supporting the frequency modulation of the distribution grid. Furthermore, they are highly efficient when coupled with steam-based bottoming cycle. The efficiency at part load is a key point to create a remunerative service system [3, 4]. All these factors are linked to penetration of renewables in the grid: the higher the penetration, the higher the capability in absorbing production fluctuations is required. New layouts are emerging including fast electrical storage [5], or Heat Pumps [4] to improve flexibility without penalizing performance. For similar reasons, the small scale microgas turbine systems are expected to improve their share in energy market as they match very well the load variations in smart grid environments, in order to assist renewable systems in energy production. The problem of small scale gas turbine is linked to their performance. Usually these systems are always based on a recuperated cycle, involving a recuperator at the exit of the compressor. The problem of the recuperator is both in terms of performance [6] 7] and long-term life [8] due to thermal cycles. In perspective, the global performance of these systems can be enhanced by considering the coupling with a fuel cell in a hybrid configuration [9], which however has a drawback on the capital costs associated to such technology. Furthermore, the emissions of GHG is in any case present and these systems can be considered environmental friendly only through a coupling with other devices or exploiting renewable fuels, such as biogas. This is why new technologies for carbon sequestration are under investigation also for these small systems 10. Nevertheless, the possibilities for fuel flexibility is higher in these small scale systems than in larger power plants. A dual fueled $100 \mathrm{~kW}$ turbine operating with natural gas and ethanol is investigated at its part load operations in [11, 12. In [13, Bauer et al. investigated operability limits for a $100 \mathrm{~kW}$ turbine burning hydrogen. These systems can be used to enhance existing technologies and to produce new layouts where renewable and fossil sources coexists: this is proposed in [14, where a hybrid photovoltaic system and a microturbine create a trigenerative power plant. Integration of microturbine in real smart grid environment is however a reality: in [15] the case study of the Savona Campus, University of Genoa (Italy), is illustrated, while in [16] an integration of micro turbine with an external solar source interacting with a ceramic storage is analyzed. This layout represents a possibility for enhancing traditional system with innovative renewable-assisted layouts. The dispatching of such systems is however dependent on ambient conditions. Considering a single smart grid, the day-ahead programming makes large uses of weather forecast- 
ing to plan which movers should be used and when, according to market-based optimization algorithms. The forecast is fundamental to understand what is expected from renewable systems as well. The forecast is useful also to estimate the required availability of the traditional energy systems - with consequences on system scheduling and operations. Similar procedures are carried out also for the day-ahead programming of larger power plant. Under the influence of ambient temperature, humidity and other factors, the engine performance is subject to consistent variations: ambient temperature is certainly the ambient parameter having the largest impact on a specific installation. In [17, 18, the decrease in power with the ambient temperature increase is considered to be greater as the size of the system is reduced. In small scale systems, the maximum power results to be capped as temperature increases and the share between electric and thermal production changes [14, 19, 20]. In [21] a study carried out with neural networks based on experimental data highlighted that the main parameter affecting the performance (i.e. electric power and efficiency) is the compressor inlet temperature, whilst ambient pressure and humidity have e negligible influence on the system performance of small scaled engine. In 19] experimental curves were introduced to outline the influence of the ambient temperature on turbine performance. In that case a modified version of a T100 was adopted and the inlet air temperature was controller through a heat exchanger that was installed at the compressor inlet. In [20] a similar study was carried out. This is based on the results of a detailed model, which has been previously trained against experimental data deriving from a real test plant. In 20] a traditional engine equipped for advanced testing in a laboratory was considered.

The present work focuses on a Turbec T100 and its performance through a series of operations with different ambient temperatures. The analyzed engine is a standard out-of-the-box T100 generating energy for the smart grid test rig and the Savona campus. The goal is to compare the correction curves proposed in [19] and in [20], which were measured on a modified machine, against data obtained from several hundred hours of real operation of a standard machine. In the end a characterization can be outlined.

\section{TEST RIG DESCRIPTION}

The work is based on field data from a T100 micro turbine (Fig. 1). This engine is derived from experience obtained by Volvo in automotive powertrains in the '80s. The specific engine under investigation was produced in 2008 and installed in Savona campus [15] in late 2011 and operates since 2012 until nowadays. The T100 is based on a recuperated cycle and generates $100 \mathrm{~kW}$ of net electrical power and $150 \mathrm{~kW}$ of thermal power, revolving at $70000 \mathrm{rpm}$. The system is installed outdoor in the Innovative Energy System

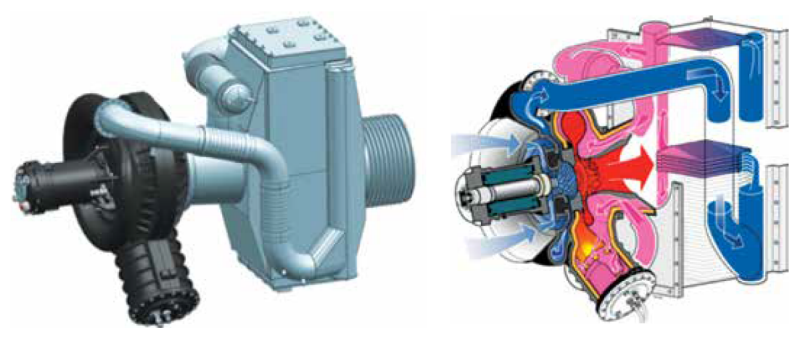

Figure 1. Powertrain representation of the T100.

\begin{tabular}{ll}
\hline Electrical Power & $100 \mathrm{~kW}$ \\
Thermal Power & $150 \mathrm{~kW}$ \\
Efficiency & $30 \%$ \\
Pressure Ratio & 4.5 \\
Fuel consumption & $7.2 \mathrm{~g} / \mathrm{s}$ \\
Turbine Inlet Temperature & $950^{\circ} \mathrm{C}$ \\
Rotational Speed & $70000 \mathrm{rpm}$ \\
\hline
\end{tabular}

TABLE 1. Nominal performance of the T100@ $15^{\circ} \mathrm{C}$.

Laboratory (IES Lab) of the Thermochemical Power Group (TPG), University of Genoa (UNIGE) [22].

The system is provided with a centrifugal single stage compressor and a radial turbine operating with a nominal pressure ratio of 4.5 and a TIT of $950{ }^{\circ} \mathrm{C}$. The analyzed system is equipped with an embedded fuel compressor. Since the engine was installed in 2011 and never modified nor special operations were carried out on the system since then, the electronics, control system and hardware are still the original as provided by Turbec. According to the nominal data, the engine consumes at full load $7.2 \mathrm{~g} / \mathrm{s}$ of natural gas for a net electrical efficiency of 0.3 . In Table 1 a summary of the nominal values is reported.

The engine is installed in a smart grid environment 23, 24 and it is part of the campus Smart Polygeneration Microgrid (SPM). The thermal energy delivery system is based on two rings, which drive water to the customers (the hot side, kept at $75^{\circ} \mathrm{C}$ ) and return it back to the recovery system of the generators (the cold side, at $55^{\circ} \mathrm{C}$ ) 23, 24. The system is equipped with local energy storage for each generator and a grid vessel of $5000 \mathrm{l}$ capable of storing up to $400 \mathrm{MJ}$ thermal energy. The whole system is governed through LabView ${ }^{\circledR}$ and can interact with a real time Matlab/Simulink station via UDP. Further information can be found in $[23,25,26$.

Since the main background is given by [19] and [20, a brief description of those work is here provided. In 20 an operating test rig was not presented. The results were obtained through a model trained against a real test rig. Still, the obtained results are derived from a model of a commercial T100. No information of operating hours and startups were provided. The model was used to outline different operative charts, presenting the operating conditions from which the influence of the ambient was evaluated. In the end, percentage linear variations of electrical power and ef- 
ficiency, thermal power and efficiency, thermal to load ratio are given [20]. These variations were outlined considering a $1^{\circ} \mathrm{C}$ growth of ambient temperature from $15^{\circ} \mathrm{C}$ condition. In [19] the approach was different: a real test rig based on a T100 was operated at controlled compressor inlet conditions. The procedure gave light to a series of correction curves that were obtained controlling the temperature at the inlet of the compressor through a heat exchanger. The engine was running in steady-state conditions. The atmosphere of the room was controlled itself and the humidity of the inlet air was approximately constant throughout the test. Those correction curves were built focusing on electrical power output, thermal power output and fuel consumption. Three different intake temperatures have been considered for that investigation: $17^{\circ} \mathrm{C}, 22^{\circ} \mathrm{C}$ and $27^{\circ} \mathrm{C}$. The present work compares the two results obtained in [19, 20] and validates the two approaches on the basis of the field data from an operating engine in standard layout. The papers [19, 20] investigate the influence of inlet conditions on the electrical and thermal power variations - and this work is focused on them. The target engine delivers cogenerative energy to the Savona campus of UNIGE and operates mainly during the cold season. During the summer season, when few students live at the campus, the engine is usually switched off. In the campus there is a set of generators, which always operates to feed the campus consumptions and another set which is used for backup operation or experimental tests. The investigated T100 belongs to this second group. As a consequence, since the turbine was installed in 2012, the engine has performed a significant amount of startups (almost 400) and severe transient operations.

\section{EXPERIMENTAL DATA ANALYSIS}

In the current analysis, information on air humidity and ambient pressure were not considered, as it is recognized that they have a lower order impact on performance, while the main environmental variable for this small system is considered to be the inlet temperature [21]. As stated previously, the investigated engine operated several years for experimental testing or generating energy for the campus grid. This means that the engine was very stressed (in test rig configuration, the system was mainly used to test smart control systems) with several start-ups. In particular, during test rig configuration, rapid transients were very frequent due to the controlling tests that have been carried out $[23 \sqrt[26]{2}$. Therefore, all of the data available have been filtered in order to consider only steady-state conditions at the desired temperatures. In particular:

- The data were considered agreeable if far enough from cold conditions i.e. this analysis considers only working points obtained 20 minutes from the startup;

\begin{tabular}{ccc}
\hline & Correction 1 [19] & Correction 2 [20] \\
\hline$P_{e l}$ & $-0.92 \%$ & $-1.22 \%$ \\
$P_{t h}$ & $+1.19 \%$ & $-0.10 \%$ \\
\hline
\end{tabular}

TABle 2. Variation obtained in 19 per each $1^{\circ} \mathrm{C}$ from $17^{\circ} \mathrm{C}$; variation obtained in $\left[20\right.$ ] per each $1^{\circ} \mathrm{C}$ from $15^{\circ} \mathrm{C}$.

- A working point was considered to be stable if the electrical power derivative was lower than $0.05 \mathrm{~kW} / \mathrm{s}$ in absolute value;

- Ambient condition were centered around $\pm 0.5^{\circ} \mathrm{C}$ for each condition;

In [19] a set of correlations was proposed to link energy production and fuel consumption to the compressor intake temperature (in general, intake temperature is equivalent to ambient temperature, unless air conditioning units are employed before the filters). These are reported in equations 1,3 and define the variation of each parameter, starting from $17^{\circ} \mathrm{C}$ ambient temperature.

$$
\begin{aligned}
\frac{\dot{m}_{f}}{\dot{m}_{f, 0}} & =1+0.0047 \cdot \Delta T \\
\frac{P_{e l}}{P_{e l, 0}} & =1-0.0092 \cdot \Delta T \\
\frac{P_{t h}}{P_{t h, 0}} & =1+0.0119 \cdot \Delta T
\end{aligned}
$$

In [20] no correction curves were defined, but a percentage variation linked to ambient conditions. In particular in 20] it stated that, for each $1^{\circ} \mathrm{C}$ growth from $15^{\circ} \mathrm{C}$, the system undergoes:

- a reduction of electrical power of $1.22 \%$

- a reduction of electrical efficiency of $0.51 \%$

- a reduction of thermal power of $0.10 \%$

- an increase in thermal efficiency of $0.70 \%$

- an increase of the thermal to electrical power ratio of $1.30 \%$

Normalizing the results of the two cited works, the percentage variation of electrical and thermal power for each increase of $1^{\circ} \mathrm{C}$; from the standard ambient temperature, results in Table 2 are obtained for comparison.

In this work, data analysis is focused around the first operating year, i.e. the 2012. During that year, the T100 experimented 115 startup for 450 operative hours. Data were filtered on the basis of the aforementioned methodology. Three different graphs gather the operating points as a function of three different intake temperatures: $12^{\circ} \mathrm{C} 15^{\circ} \mathrm{C}$ and $27^{\circ} \mathrm{C}$. With respect to previous work [19], different temperature values where considered, still the proposed range of temperature is useful to understand the behavior of the engine both 


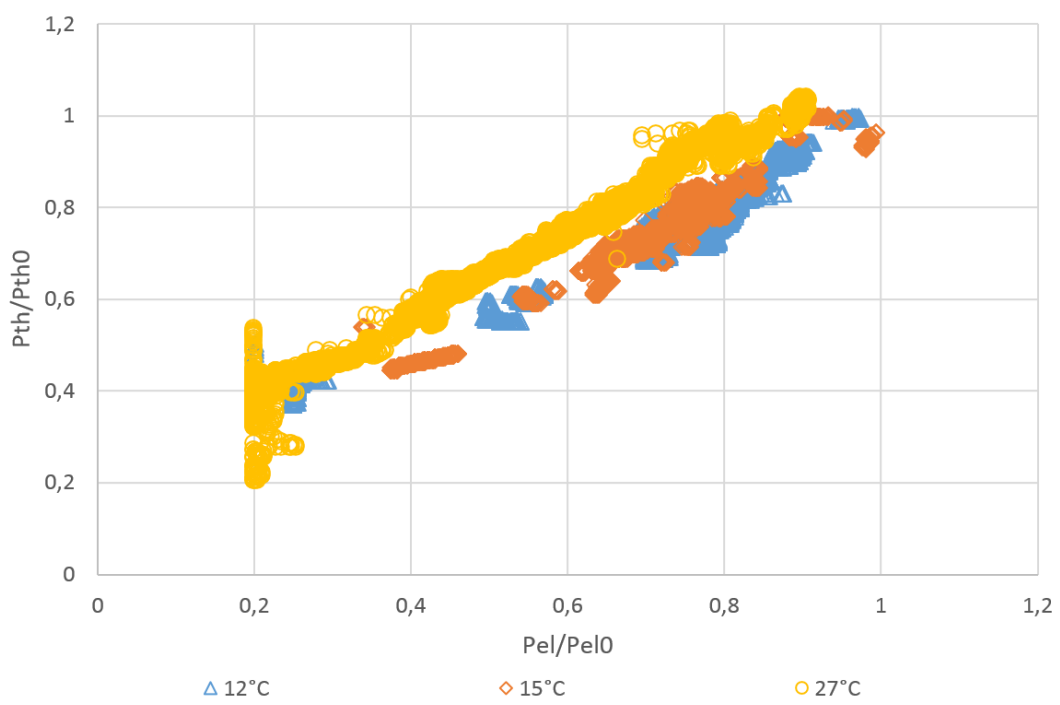

FiguRE 2. Operatinal field data for three ambient temperatures.

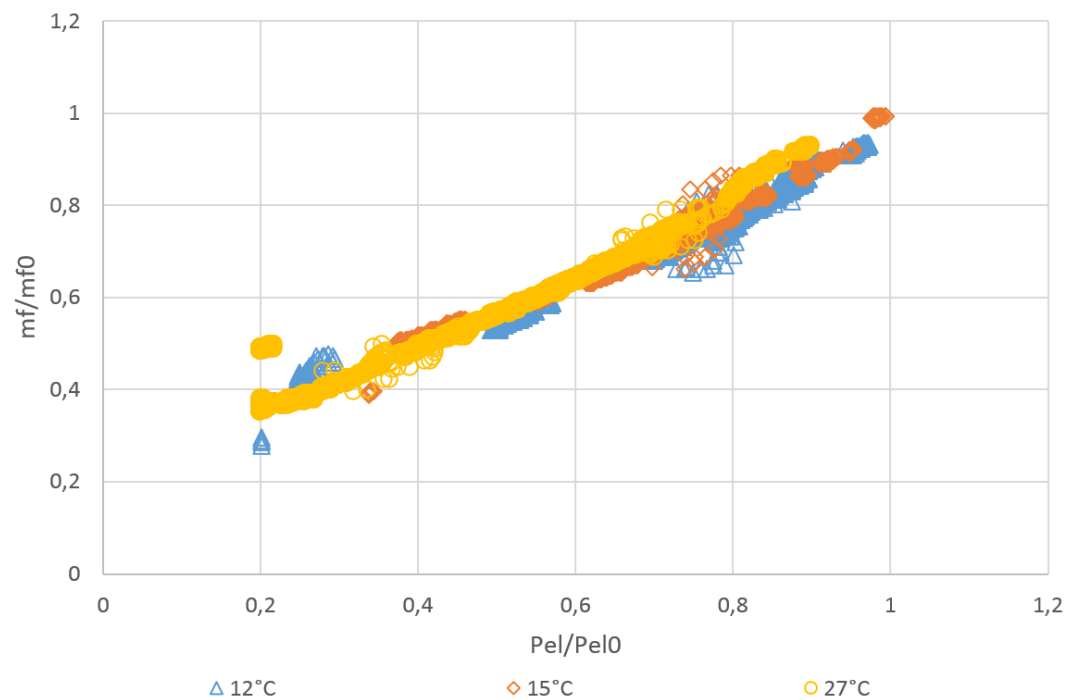

FiguRE 3. Fuel consumption for operating points at three different ambient temperatures.

under and over the $15^{\circ} \mathrm{C}$. The investigated parameters are electric power, thermal power, fuel consumption and electric efficiency. All values are normalized on the basis of the nominal data included in Table 1 Electric efficiency is a parameter computed during the data analysis, considering equation 4 , with LHV equal to $41 \mathrm{MJ} / \mathrm{kg}$.

$$
\eta=\frac{P_{e l}}{\dot{m}_{f} \cdot L H V}
$$

Figure 2 shows collected raw data for three ambient temperatures: below $15^{\circ} \mathrm{C}$ the performance remains similar, while a shift is evident for $27^{\circ} \mathrm{C}$. In particular, while increasing the ambient temperature, the reduction of maximum electric power is noticed, as well as a small increase in thermal power production. This is in agreement with 19, since the proposed correction curves give a reduction in electric power and augmentation in thermal power as ambient tempera- ture increases (see Table 2). Figure 3 shows the same operating points but focuses on fuel consumption: in this case, the variation is small and the points are distributed around the same line. The influence on efficiency is given by Figure 4, where the impact on peak efficiency $(-4.5 \%)$ and efficiency at maximum load $(-3.7 \%)$ is clearly visible.

From these data, validation of the curves [19, 20] has been carried out. In particular, a series of points around the maximum load has been collected and averaged per each of the investigated temperature. As a consequence, the field data included in Figure 59 and $5 \mathrm{~b}$ are mean values of operating points at maximum load. The same figure shows two trend lines: correction curve 1 and 2 . These are the trend lines obtained from [19] and [20], respectively.

From figure $5 \mathrm{a}$ it is clear that in general the correction curve 2 overestimates the reduction in electric power linked to intake temperature variation, while 


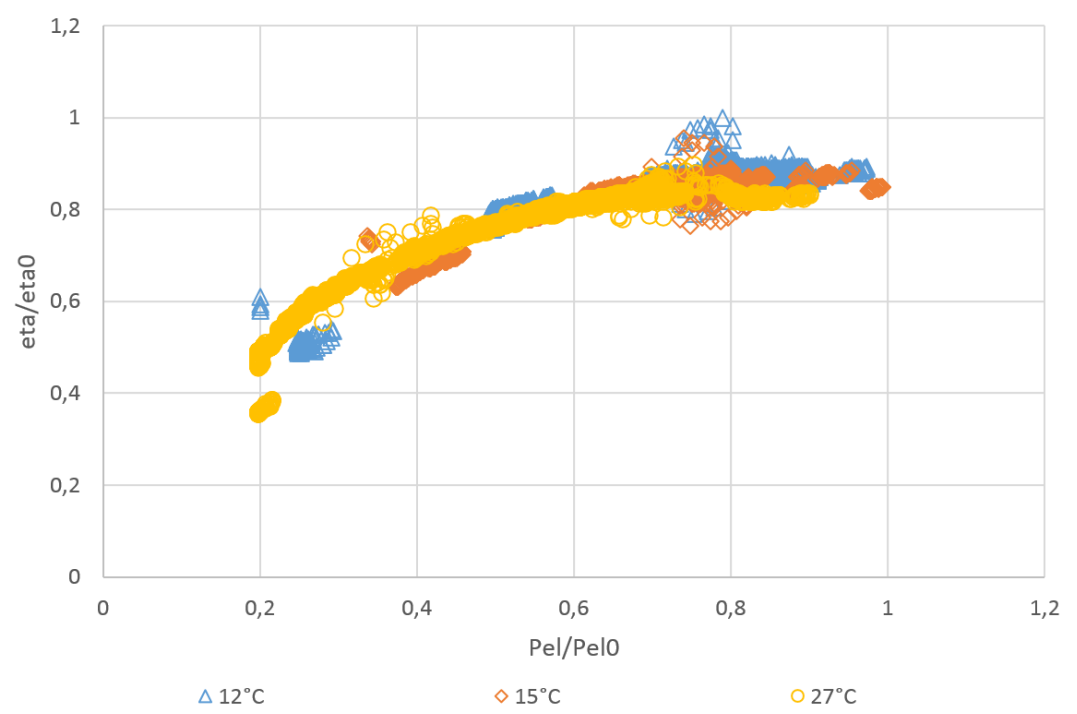

FiguRE 4. Variation of efficiency as a function of electric load and ambient temperature.
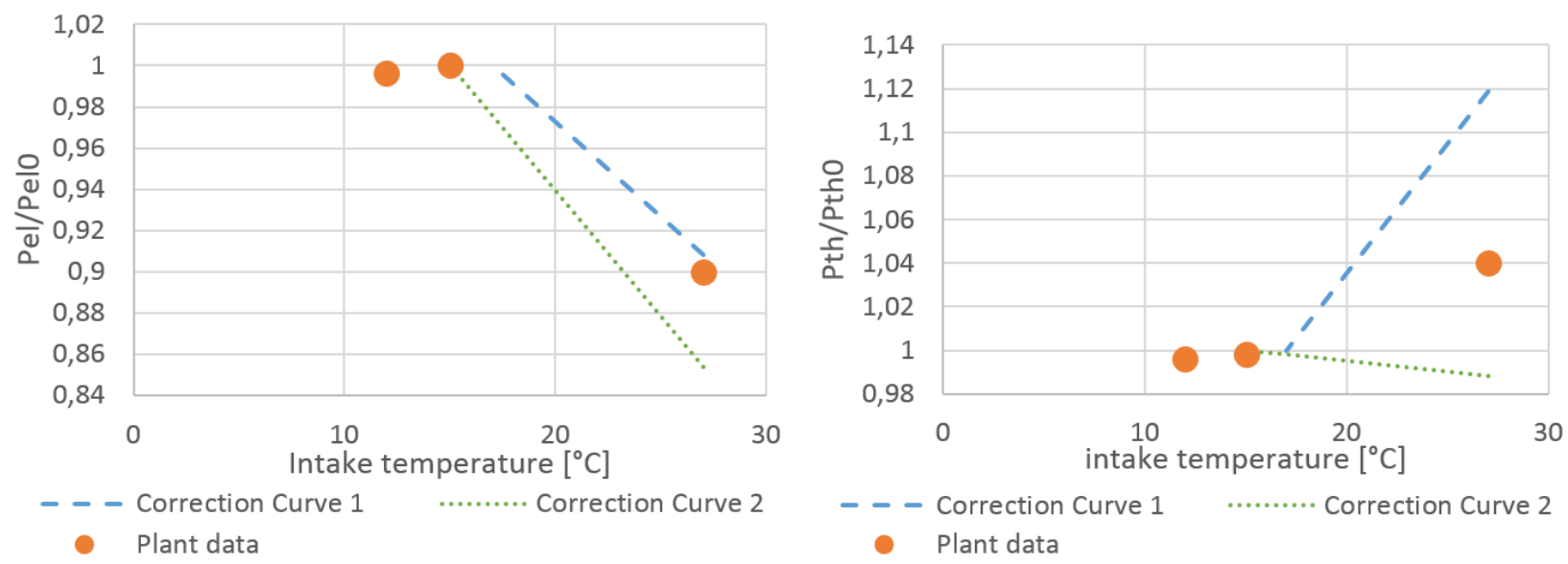

FiguRE 5. (a) Operating points for electric power production and (b) for thermal power production as a function of ambient temperature.

the correction curve 2 slightly underestimates the same variation. In $5 \mathrm{~b}$ the thermal variation is consistent with correction curve 2 - even though this overestimates the variation. The correction curve 1 , as proposed by [20], shows a small negative trend, which is clearly not in agreement with the real behavior of the engine.

\section{Degradation due to Aging}

A system degradation can be in general defined as a deterioration in quality, level or standard of performance of the system due to different reasons. In energy power plant, a degradation of performance is expected during lifetime. The effect of aging on system degradation is linked to all of those components prone to wear and tear. The large availability of field data allowed preliminary short analysis on ageing of the engine. As stated before, the investigated T100 was installed outdoor, exploited to perform numerous startups (related to the actual operating hours) and

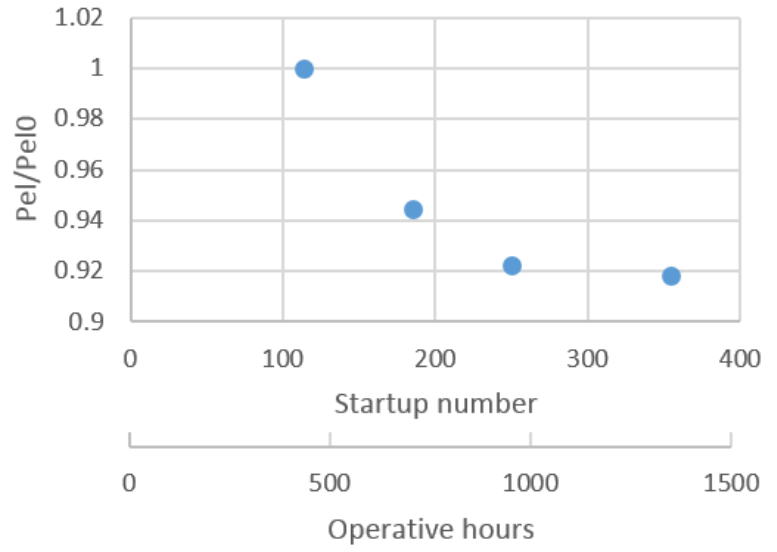

Figure 6. Maximum electrical power as a function of the number of startups. 

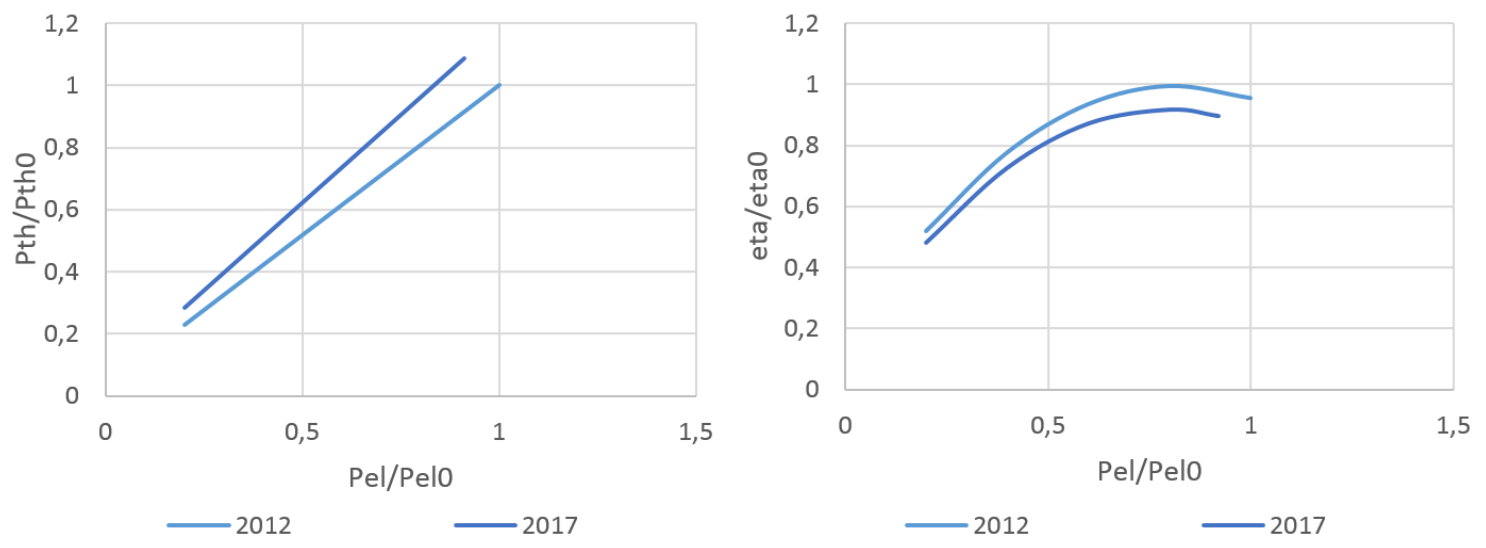

Figure 7. Performance trend of the engine at $15^{\circ} \mathrm{C}$ ambient temperature for (a) electrical and thermal power and (b) efficiency, as a function of electrical power.

underwent severe operating cycles, linked to series of rapid transients to test the control system performance. For these reasons, performance degradation of the system was, in the end, evident. The analysis here proposed is mainly based on the number of startups of the system: in general, each startup event can be associated to a number of equivalent operating hours, which affect significantly the system performance and cause degradation. The investigated T100 underwent 360 startups against only 1400 operating hours; therefore the impact of the startups can be considered preeminent on the aging of the system. In particular, here the variation of engine maximum power is analysed as a function of the number of startups. This has been conducted with compressor intake temperatures around $15^{\circ} \mathrm{C}$, which guarantees the nominal performance of the engine. Figure 6 reports the means of maximum electrical power versus cumulative startups. The reduction in power with the startup number is evident: the second axis of the figure shows the number of operating hours at each startup. It is evident a quadratic shape in power degradation with respect to startup number.

Finally, two images summarizes how the performance of the engine changed over the years: Figure $7 \mathrm{a}$ shows the trend line at $15^{\circ} \mathrm{C}$ for the first year of operations of the engine (same data showed in Figs. 22- 4) compared to the current trend line obtained in the same operative conditions. These points were obtained analyzing the last year of operation of the engine with the same criteria adopted for the data analyzed previously. A decrease in maximum power is evident, which reflects on increase of thermal production side. Figure $7 \mathrm{~b}$ shows the same comparison for electrical efficiency. Consistently with the trend of performance, the efficiency is reduced both at its maximum peak and at maximum load (-7.5\% and $-5 \%$ respectively, on relative basis).

\section{Conclusions}

The analysis of T100 microturbine performance is based on real operating data at various ambient tem- peratures obtained in different laboratories and test rigs. The study outlined the differences of behavior of the system against the two proposed model. Three different temperatures have been considered by the analysis. The data at $12{ }^{\circ} \mathrm{C}$ were in agreement with those at $15^{\circ} \mathrm{C}$, i.e. without showing significant variation in performance. An influence on the performance is indeed evident as the intake temperature rises. Considering the ambient effect, on the analyzed T100, it has been highlighted that:

- The electrical power is reduced by $0.83 \mathrm{~kW} /{ }^{\circ} \mathrm{C}$ per each $1{ }^{\circ} \mathrm{C}$ growth from $15^{\circ} \mathrm{C}$

- The thermal power is increased by $0.5 \mathrm{~kW} /{ }^{\circ} \mathrm{C}$ per each $1{ }^{\circ} \mathrm{C}$ growth from $15^{\circ} \mathrm{C}$

- The efficiency is reduced by $0.31 \% /{ }^{\circ} \mathrm{C}$ per each $1{ }^{\circ} \mathrm{C}$ growth from $15{ }^{\circ} \mathrm{C}$

In addition, some information based on the aging of the system has been derived, showing a clear decrease in maximum output power based on the number of startups. Nevertheless, this analysis cannot be used to define a parameter for the aging of the system due to severe working conditions and frequency of startups and shutdowns against the effective operating time. What it can be concluded is that the engine, which has been never subject to maintenance and/or cleaning over the years, shows a clear reduction in performance - and it stabilizes around a loss of $8 \%$ from design value. Even though a quadratic shape is evident, it is useful to quantify an average of performance losses paid by each start-up. In this way it would be possible to determine the impact in terms of equivalent hour associated to each startup procedure. Giving that, the average losses can be quantified in terms of:

- A reduction in electrical power of $0.022 \%$ per startup in relative terms

- A reduction in efficiency at full load of $0.014 \%$ per startup in relative terms

In the end, the analysis can be used to give light to a simplified dynamic model able to describe the engine 
performance and the influence the intake temperature has on its performance. The model can be constituted by two transfer functions which represent the electrical and thermal output to input variations. These are coupled with a temperature-dependent parameter as obtained from the analysis, for off-design correction. This model can be eventually used to estimate performance variation due to ambient temperature variation, for instance, when the compressor intake temperature can be artificially modified through inlet conditioning techniques. The study shows also that what was obtained in [19] and [20] is reasonably repeatable, in particular for the electrical power. However, the proposed correction curves for thermal power shows a significant spread with respect to field data.

\section{ACKNOWLEDGEMENTS}

This research work has been carried out within the PUMP-HEAT project, which has received funding from the European Union's Horizon 2020 research and innovation programme under grant agreement No 764706 .

\section{REFERENCES}

[1] M. de Groot, W. Crijns-Graus, R. Harmsen. The effects of variable renewable electricity on energy efficiency and full load hours of fossil-fired power plants in the european union. Energy 138:575 - 589, 2017. DOI:10.1016/j.energy.2017.07.085

[2] J. Devlin, K. Li, P. Higgins, A. Foley. Gas generation and wind power: A review of unlikely allies in the United Kingdom and Ireland. Renewable and Sustainable Energy Reviews 70:757 - 768, 2017. DOI:10.1016/j.rser.2016.11.256

[3] M. Variny, O. Mierka. Improvement of part load efficiency of a combined cycle power plant provisioning ancillary services. Applied Energy 86(6):888 - 894, 2009. DOI:10.1016/j.apenergy.2008.11.004

[4] A. Giugno, A. Cuneo, A. Sorce, L. Piantelli. Integration of heat pump and gas turbine combined cycle: layout and market opportunity. In Proceedings of IGTC 18, Bruxelles. 2018.

[5] T. Ayodele, A. Ogunjuyigbe. Mitigation of wind power intermittency: Storage technology approach. Renewable and Sustainable Energy Reviews 44(C):447-456, 2015.

[6] M. L. Ferrari, A. Sorce, M. Pascenti, A. F. Massardo. Recuperator dynamic performance: Experimental investigation with a microgas turbine test rig. Applied Energy 88(12):5090 - 5096, 2011. DOI:10.1016/j.apenergy.2011.07.016

[7] J. Cai, X. Huai, W. Xi. An optimal design approach for the annular involute-profile cross wavy primary surface recuperator in microturbine and an application case study. Energy 153:80 - 89, 2018. DOI:10.1016/j.energy.2018.04.016

[8] W. J. Matthews, K. Leslie More, L. R. Walker. Longterm microturbine exposure of an advanced alloy for microturbine primary surface recuperators. Journal of Engineering for Gas Turbines and Power-transactions of The ASME 131:032301-6, 2009. DOI:10.1115/1.2966419
[9] M. A. Azizi, J. Brouwer. Progress in solid oxide fuel cell-gas turbine hybrid power systems: System design and analysis, transient operation, controls and optimization. Applied Energy 215:237 - 289, 2018. DOI:10.1016/j.apenergy.2018.01.098

[10] S. Giorgetti, L. Bricteux, A. Parente, et al. Carbon capture on micro gas turbine cycles: Assessment of the performance on dry and wet operations. Applied Energy 207:243 - 253, 2017. Transformative Innovations for a Sustainable Future - Part II, DOI:10.1016/j.apenergy.2017.06.090

[11] S. Camporeale, B. Fortunato, T. Marco, et al. Part load performance and operating strategies of a natural gas - biomass dual fueled microturbine for combined heat and power generation. Journal of Engineering for Gas Turbines and Power 137, 2014. DOI:10.1115/1.4030499.

[12] M. Braun-Unkhoff, J. Dembowski, J. Herzler, et al. Alternative fuels based on biomass: An experimental and modeling study of ethanol co-firing to natural gas. vol. 137. 2014. DOI:10.1115/1.4029625

[13] S. Bauer, B. Hampel, T. Sattelmayer. Operability limits of tubular injectors with vortex generators for a hydrogen-fueled recuperated $100 \mathrm{kw}$ class gas turbine. Journal of Engineering for Gas Turbines and Power 139, 2017. DOI:10.1115/1.4035842

[14] F. Basrawi, T. Yamada, S. Obara. Economic and environmental based operation strategies of a hybrid photovoltaic-microgas turbine trigeneration system. Applied Energy 121:174 - 183, 2014. DOI:10.1016/j.apenergy.2014.02.011

[15] S. Bracco, F. Delfino. A mathematical model for the dynamic simulation of low size cogeneration gas turbines within smart microgrids. Energy 119:710 723, 2017. DOI:10.1016/j.energy.2016.11.033

[16] A. Traverso, S. Barberis, D. Lima, A. F. Massardo. Dynamic analysis of concentrated solar hybridised gas turbine. In Proceedings of ASME Turbo Expo 2014: Turbine Technical Conference and Exposition, vol. 3A, p. V03AT07A005. 2014. DOI:10.1115/GT2014-25225

[17] B. Mohanty, G. Paloso. Enhancing gas turbine performance by intake air cooling using an absorption chiller. Heat Recovery Systems and CHP 15(1):41 - 50, 1995. DOI:10.1016/0890-4332(95)90036-5

[18] A. A. Amell, F. J. Cadavid. Influence of the relative humidity on the air cooling thermal load in gas turbine power plant. Applied Thermal Engineering 22(13):1529 - 1533, 2002. DOI:10.1016/S1359-4311(02)00063-7.

[19] M. L. Ferrari, A. Traverso, A. F. Massardo. Smart polygeneration grids: experimental performance curves of different prime movers. Applied Energy 162:622 630, 2016. DOI:10.1016/j.apenergy.2015.10.144.

[20] F. Caresana, L. Pelagalli, G. Comodi, M. Renzi. Microturbogas cogeneration systems for distributed generation: Effects of ambient temperature on global performance and components' behavior. Applied Energy 124:17 - 27, 2014. DOI:10.1016/j.apenergy.2014.02.075

[21] C. Bartolini, F. Caresana, G. Comodi, et al. Application of artificial neural networks to micro gas turbines. Energy Conversion and Management 52(1):781 - 788, 2011. DOI:10.1016/j.enconman.2010.08.003. 
[22] M. Rivarolo, A. Cuneo, A. Traverso, A. Massardo. Design optimisation of smart poly-generation energy districts through a model based approach. Applied Thermal Engineering 99:291 - 301, 2016. DOI:10.1016/j.applthermaleng.2015.12.108

[23] M. L. Ferrari, M. Pascenti, A. Sorce, et al. Real-time tool for management of smart polygeneration grids including thermal energy storage. Applied Energy 130:670 - 678, 2014. DOI:10.1016/j.apenergy.2014.02.025

[24] A. Cuneo, M. Ferrari, M. Pascenti, A. Traverso. State of charge estimation of thermal storages for distributed generation systems. Energy Procedia 61:254 - 257, 2014. International Conference on Applied Energy, ICAE2014, DOI:10.1016/j.egypro.2014.11.1101.
[25] M. L. Ferrari, A. Traverso, M. Pascenti, A. F. Massardo. Plant management tools tested with a small-scale distributed generation laboratory. Energy Conversion and Management 78:105 - 113, 2014. DOI:10.1016/j.enconman.2013.10.044.

[26] I. Rossi, L. Banta, A. Cuneo, et al. Real-time management solutions for a smart polygeneration microgrid. Energy Conversion and Management 112:11 - 20, 2016. DOI:10.1016/j.enconman.2015.12.026. 